\title{
Contato Improvisação como uma Arte de viver [parte 4]
}

\section{Contact Improvisation as an Art of living [part 4]}

Jörg Schmid ${ }^{1}$

Tradução e Notas: Bruno Garrote M. ${ }^{2}$ 


\section{Resumo}

A presente tradução é a continuação de um projeto de tradução, apoiado e incentivado pela revista Urdimento, relativo a partes do doutorado Contato Improvisação como uma Arte de viver, de Jörg Schmid da Universidade Philipps de Marburgo. Essa é a quarta tradução, [parte 4], desse projeto, a qual foca na atenção plena (mindfullness ou Achtsamkeit), diferentes práticas de meditação, correlatos neurobiológicos da atenção plena, diferenciação entre atenção plena direcionada e não-direcionada, atenção plena no contexto terapêutico, paradoxo da não-intencionalidade intencional, saúde corporal e psíquica, repercussões da atenção plena no bem-estar subjetivo, atenção plena e o presente, desdobramentos de práticas meditativas no corpo durante a atividade e durante o dia-a-dia etc. Essa tradução pretende continuar contribuindo para o cenário da dança e dos estudos performáticos, mostrando a importância do Contato Improvisação (Cl) como uma crescente e mundialmente disseminada forma de dança contemporânea e pesquisa de movimento corporal, ainda pouco estudada no Brasil.

Palavras-chave: Contato improvisação; dança; performance; história.

\section{Abstract}

This translation is the continuation of a translation project, supported and encouraged by the periodical Urdimento, referring to sections of the doctorate Contact Improvisation as an Art of living of Jörg Schmid from the University Philipps Marburg. This is the fourth translation, [part 4], of this project, which focuses on mindfulness (Achtsamkeit), different meditation practices, neurological correlations of mindfulness, differentiation of directed and undirected mindfulness, mindfulness in the therapeutic context, paradox of the intentional non-intentionality, bodily and psychological health, repercussions of mindfulness in the subject well-being, mindfulness and the present, outcomes of meditative practices in the body during activities and during the day-to-day etc. This translation intends to keep contributing to the scene of dance and performance studies, showing the importance of Contact Improvisation (Cl) as a growing and worldly disseminated form of contemporary dance and bodily movement research, yet scarcely studied in Brazil.

Keywords: Contact improvisation; dance; performance; history. 


\section{NOTA DO TRADUTOR}

Essa é a quarta tradução [parte 4] desse projeto de tradução da tese de doutorado de Jörg Schmid pela Faculdade de Educação da Universidade Philipps de Marburgo, 2011; relativa às páginas 38 a 55 do texto original. A [parte 1] foi publicada na revista Urdimento, v.1, n.28, p. 302-322, Julho 2017. A [parte 2] foi publicada na revista Urdimento, v.2, n.29, p. 177-192, Outubro 2017. A [parte 3] foi publicada na revista Urdimento, v.3, n.30, p. 112-139, dezembro 2017. E a tese completa em alemão pode ser encontrada no seguinte link disponível gratuitamente pelo autor (em seu site pessoal) e pela universidade: http://joerg-lemmer-schmid.de/index.php?id=6 - Acesso em: 19 dez. 2016.

Os [colchetes] ao longo desta tradução marcam as manifestações e/ou as notas do tradutor no intuito de facilitar a leitura por meio de comentários ou trazendo termos em alemão, no original.

Tentou-se manter a disposição das imagens/figuras, tabelas, separação de subtítulos etc. da maneira mais fiel possível ao texto original. Outrossim, não se alterou a numeração original dos títulos e subtítulos - deste modo, esse texto, ou suas imagens/figuras, não se inicia com o número "1", uma vez que se trata de uma seção já no meio da tese.

Mesmo esta tese de doutorado tendo sido disponibilizada pública e gratuitamente pelo autor e pela universidade; por uma questão de cortesia, o tradutor consultou o autor Jörg Schmid sobre esta tradução para o português e ele entusiasmadamente apoiou esse projeto e afirmou não ter problema nenhum a respeito de direitos autorais e de publicação desta tradução.

O formato de citação e referências bibliográficas foram mantidas assim como estavam no original alemão, no intuito de não alterar o estilo do autor e também por ser um formato claro, facilmente compreensivel e semelhante à metodologia de pesquisa acadêmica brasileira.

Boa leitura. 


\title{
2.3. Atenção Plena ${ }^{3}$
}

\begin{abstract}
"Se você permanecer aberto e atento e usar uma das técnicas para sempre ir melhorando o seu espírito, a sua negatividade gradualmente se evaporará. Você começa a se sentir bem consigo mesmo, você se sente, como se diz, 'bem em sua pele'. Isso resulta em um relaxamento e em uma profunda serenidade. Eu considero esta prática como a mais eficaz terapia e auto-cura ".

(Sogyal Rinpoche) $)^{4}$
\end{abstract}

Em uma breve introdução ao uso do conceito de atenção plena, vários aspectos da atenção plena serão esclarecidos para uma compreensão mais profunda. Antes de considerar a atenção plena no contexto da qualidade de vida, seguirá uma descrição da sua aplicação em contextos psicoterapêuticos, assim como uma diferenciação dos mecanismos de ação subjacentes básicos. Por fim, as descobertas mais positivas sobre a atenção plena serão submetidas à uma reflexão crítica e resumidas.

\section{Introdução ao conceito de atenção plena}

O conceito de atenção plena originado da sabedoria oriental é geralmente descrito na cultura ocidental como a consciência [Bewusstsein] e a atenção [Aufmerksamkeit] diante da experiência presente. "Em uma visão budista, a atenção inclui uma série de dimensões não apenas cognitivas, mas também emocionais, sociais e éticas, nas quais ela está inserida e que vai muito além da divisão tradicional entre atenção e consciência da psicologia científica", esclarece Paul Grossman, que introduziu estudos pioneiros em reflexões científicas sobre a atenção plena na Alemanha (ver Grossmann, 2006, 71). Em sua opinião, muitos aspectos da psicologia budista são muito pouco considerados na tradição de pesquisa ocidental, como, p.ex., a intenção de cultivar a amabilidade, paciência, tolerância, gentileza e compaixão (ibid., 75). Em um grande número das propostas de definição científica ligeiramente diferentes entre si são igualmente compreendidos como parte da atenção diferentes aspectos, tais como a abertura diante do novo, atenção para a diferença, sensibilidade para diferentes contextos e uma consciência de múltipla perspectivas em graus variados. O núcleo comum a todas as definições pode ser descrito da seguinte forma: atenção plena é uma imediata e contínua consciência sobre sensações corporais [körperlicher], percepções, estados afetivos [Affektzustände], pensamentos e ideias, sem, todavia, refletir sobre isso, procurar soluções ou, de qualquer modo, reagir imediatamente (ver Grossmann 2006 73).

Bishop et al. (2004) entendem que duas habilidades centrais estão na base dessa compreensão sobre a atenção. Por um lado, é necessária uma forma de auto-regulação e tendência para a atenção plena e, por outro lado, deve-se ter uma postura

\footnotetext{
${ }^{3}$ [Atenção plena é a expressão que escolhi em português para traduzir o termo alemão Achtsamkeit. O sufixo -keit transforma, em alemão, um adjetivo em um substantivo; não somente tornando abstrato um adjetivo, mas também trazendo consigo uma ideia de "estado/capacidade/habilidade de...". Assim como em português temos, por exemplo, funcional e funcionalidade ou fácil e facilidade etc; em alemão há o adjetivo achtsam, que pode ser traduzido como atento, e o substantivo criado com o sufixo -keit, formando Achtsamkeit, ou seja, literalmente algo como "atencionalidade" "atentionalidade". E, a saber, seria confuso e limitador traduzir simplesmente por "atenção", uma vez que se costuma traduzir Aufmerksamkeit por atenção e isso seria problemático, pois esse termo também aparece bastante nesse texto. Por esse e outros motivos, optou-se por atenção plena, no intuito de já entrar em uma tendência internacional de se utilizar uma expressão e/ou termo próprio em cada língua para tentar designar essa ideia/conceito específico, que atualmente é muito difundido no termo inglês mindfulness.] ${ }^{4}$ Rinpoche, S. (1995, Texto 2. Dezembro)
} 
de aceitação e boa vontade [wohlwollende] diante da experiência momentânea (ver Bishop et al., 2004, 232). Após esta definição operacional, a atenção plena pode ser compreendida tanto como um processo metacognitivo, quanto como uma cognição sobre a cognição. O constante "fluxo" do próprio pensamento se torna o objeto de observação, sem se perder com isso a atenção plena para o momento presente. Isto significa que o pensamento e o impulso da ação são, inicialmente, apenas percebidos e desconectados em uma distância reflexiva de uma reação comportamental imediata. Uma metáfora adequada para a atenção plena é o engatar de uma marcha no carro. Mesmo quando o motor continua funcionando, ele está separado das marchas e a sua força não pode ser alterada em movimento. A postura fundamental de aceitação também significa aceitar situações disconfortáveis assim como são, sem entrar em uma postura de resistência.

A seguir, vários aspectos da atenção plena serão descritos detalhadamente. Então, os processos cognitivos básicos subjacentes da atenção plena serão mostrados de forma diferenciada. Na sequência, entraremos na relação da consciência consigo mesma, a percepção da própria personalidade. Por consequência, formas básicas de meditação serão apresentadas enquanto práticas de atenção plena e colocadas em conexão com atuais resultados de pesquisas neurofisiológicas.

\section{Atenção plena como consciência e como processo de atenção}

A percepção da realidade está intimamente relacionada ao foco da nossa atenção. Somente aquilo que penetra na nossa consciência parece ser real. Todo o resto desaparece e é inexistente para o indivíduo no momento. O filósofo americano e pioneiro da psicologia moderna William James descrevia essa conexão já em 1890: "A realidade se manifesta através da nossa atenção" (James, 1958, 322). A atenção plena pode ser compreendida como uma forma aprimorada de consciência e como uma focalização da atenção. Aqui se descreve a conexão entre atenção (attention), consciência [Bewusstsein] (consciousness) e consciência [Bewusstheit] enquanto consciência de fundo [Gewahrsein)] (awareness) do seguinte modo: "Consciência [consciousness] engloba consciência de fundo [awareness] e atenção [attention]. A consciência de fundo é o 'radar' no plano de fundo da consciência, continuamente monitorando o ambiente interno e externo. Pode-se estar ciente dos estímulos sem que eles estejam no centro das atenções. A atenção [attention] é um processo de focalizar conscientemente a consciência de fundo, proporcionando uma maior sensibilidade a uma gama limitada de experiências" (Brown \& Ryan 2003, 822). Quando os dançarinos de valsa conseguem manter, p.ex., a atenção para sustentar o ritmo de três quartos ou para uma sequência específica de passos, ao mesmo tempo em que subsiste uma consciência de fundo sobre a própria posição no espaço e também sobre os outros casais de dançarinos.

A consciência pode, todavia, variar muito fortemente: individualmente e situacionalmente. Dentro da consciência desperta [Wachbewusstseins], há graduações, onde impressões sensoriais, sensações, sentimentos, pensamentos, bem como fenômenos dentro de um campo, em cujo contexto elas ocorrem e são conscientemente percebidas. Os estados de consciência de fundo diferem um do outro em seu grau 
de alerta [Wachheit], como, p.ex.: coma, sono, estados intermediários de confusão, estado desperto e alta vigilância. Nesse contexto, atenção plena significa abrir a janela da percepção o máximo possível. Seguindo Edelman \& Tonino (2000), Grossmann $(2006,82)$ descreve um modelo de conscientização com diferentes níveis de consciência. Começa-se com a percepção corporal de si [Selbst], que é, evolutivamente e também pensando no desenvolvimento psicológico, o primeiro nível da consciência. Aqui, incluem-se os componentes proprioceptivos, cinestésicos, somatossensoriais e outros tais como os vegetativos e autônomos do corpo. Com base nisso, o próximo nível mais elevado das percepções é o das próprias emoções enquanto reações a condições ambientais internas e externas. Emoções consistem em um complexo padrão de estímulos fisiológicos. O próximo nível envolve o uso consciente de memórias [Erinnerungen] não-verbais, imagens mentais e também uma diferenciação em diversas categorias de experiência. Este nível é reservado para os mamíferos mais desenvolvidos e é construído com base na aquisição de linguagem dos humanos. "Com a emergência de uma ordem superior de consciência surge ao mesmo tempo uma real subjetividade, cheia de forças narrativas e metafóricas, e com conceitos de si, bem como do passado e do futuro" (Edelman \& Tonino 2000, citado por Grossman $2006,83)$.

\section{Uma consciência além da personalidade}

De uma perspectiva budista, a percepção de si muda com o estado de consciência. "O conceito de um EU estável, de uma personalidade ou de um si é onipresente na teoria psicológica ocidental e em sua aplicação. Na psicologia budista, no entanto, a ideia de um si em grande parte imutável e claramente definido ou de um sentimento de identidade individual é vista como uma ilusão, surgida em um espírito [Geist] ${ }^{5}$ que não está acostumado a deixar prevalecer uma atenção atenta e não-valorativa [nicht-wertende] de momento a momento" (Großmann 2006, 96). O objetivo da prática da atenção plena espiritual é auto-superação, ou seja, a superação do egocentrismo e do apego ao eu" [sic] ${ }^{6}$ (Anderssen-Reuster \& Altner 2007, 53). Por meio de várias técnicas da prática de atenção plena, como, p.ex., a meditação sentada, pode ocorrer a experiência de um outro estado, diferente da consciência cotidiana. Wallace (2008) fala da "consciência primordial", referindo-se a um estado de colocar-se em repouso e de reconhecimento da "verdadeira natureza do espírito [Geist]" (Wallace, 2008, 206). Ele descreve esse estado da seguinte forma: "A compreensão do espaço absoluto realizado no nível da experiência através da consciência primordial transcende todas as distinções entre sujeito e objeto, espírito e matéria, todas as palavras e conceitos" (Wallace 2008, 207). Tal visão é o "não-dual", a "compreensão realizada sobre a peculiar [wesensmässig] unidade do espaço absoluto e a consciência primordial",

\footnotetext{
${ }^{5}$ [Muitas vezes se traduz Geist por mente. Todavia, mente traz a ideia de uma instância muito fisiológica, o que claramente seria limitador para a ideia que se está trabalhando aqui. Desse modo, decidi pela tradução "espírito", por ser mais abrangente, porém entendendo que esse termo não deve fornecer asas à imaginação nem ser relacionado de forma redutora ao que se entende por "espiritismo" ou algo do tipo. Toda a discussão que poderia surgir aqui é justamente pela diferença do ocidente e oriente em tratar sobre questões da matéria e questões do espírito, diferenciações complicadas entre corpo e mente, e por todas as outras dualidades relacionadas a esse tema]

${ }^{6}$ [No texto original existe essas aspas finais, mas não há o início dela. Resolvi manter como estava, por se tratar claramente de uma citação, apesar de não se saber exatamente onde ela se inicia]
} 
vinda do nível da experiência (ibid. 207). Esse estado é denominado no zen-budismo de "vivência-satori". Ele descreve "a vivência temporária da suspensão da oposição sujeito-objeto, a qual nunca se deixa ser completamente delimitada com palavras" (Heidenreich \& Michalak 2006, 232).

No decorrer deste trabalho, os termos si [Selbst], personalidade e EU são usados da seguinte forma: O si é, como já explicado no capítulo do fluxo, a soma de todas as experiências, atitudes, valores e habilidades de uma pessoa. Essas também podem ser às vezes extremamente contraditórias. Dependendo do contexto, diferentes partes e aspectos do si podem se tornar conscientes. A personalidade é vista como uma tendência comportamental temporalmente duradoura para reagir a determinados estímulos e contextos. Mesmo que uma pessoa possa ter um humor depressivo em uma situação concreta, ela pode, todavia, ser muito aberta e feliz a partir de sua personalidade. Naquele momento, no entanto, essa pessoa pode estar consciente somente dos aspectos negativos de si. O EU é usado no sentido de Freud ${ }^{7}$. É uma instância mediadora entre as necessidades situacionais, conscientes e pré-conscientes, e os impulsos comportamentais (em termos freudianos, o Isso [ES]), bem como entre os valores e as atitudes ancorados no si (em termos freudianos, o Super-Eu [Über-Ich]), que são conscientes na situação concreta e, portanto, também comportamentalmente efetivos [verhaltenswirksam]. Por último, é o EU que pode refletir sobre as decisões e encontrá-las conscientemente. O EU é, portanto, a sede da nossa vontade.

\section{Tipos de prática de atenção plena e meditação}

Pelo termo "meditação", a maioria das pessoas imagina alguém sentado no chão com as pernas cruzadas sem se mover externamente. "Uma vez uma mulher idosa veio ao Buda e perguntou-lhe como meditar. Ele instruiu-a a tomar consciência de cada movimento de suas mãos, enquanto ela tirava água do poço; deste modo, ele sabia que se ela apenas prestasse atenção nisso, logo ela estaria nesse estado de repouso, alerta e aberto, que é a meditação" (Rinpoche, 1995, texto de 9 de novembro). De fato, existem realmente muitas formas diferentes de meditação. Sentar, caminhar e também formas de movimento como a dança podem fazer parte dela, e até mesmo canto ou práticas sexuais (Tantra). Essas formas de meditação diferenciam-se não somente em sua forma externa, mas também precisam ser diferenciadas em relação ao tipo de atividade mental durante a meditação. Existem duas técnicas fundamentalmente diferentes: "Um estilo, meditação de atenção focada, implica em focar voluntariamente a atenção em um objeto escolhido. O outro estilo, meditação de monitoramento aberto, envolve o monitoramento não reativo do conteúdo da experiência de momento a momento" (Lutz. et al. 2008, 163). Independentemente de se estar sentado parado ou em movimento, é preciso distinguir se a atenção está focada em um ponto ou uma atividade, ou se a atenção deve perceber, com todos os seus sentidos, o momento presente de forma expandida e livremente fluida, sem, com

${ }^{7}$ [A tradução brasileira tradicional para os termos freudianos Ich, Es e Über-Ich seguiu a tradução cientifista norte-americana, o que resultou em termos latim como ego, id e super-ego, respectivamente. A meu ver (e também de outros pensadores), isso foge do objetivo inicial de Freud. Deste modo, estou trazendo a tradução mais originária e próxima do alemão para esses termos, que seria Eu, Isso e Super-Eu.] 
isso, seguir um foco determinado. Paradoxalmente, na última forma de meditação, o foco está em não ter foco. Durante a meditação sentada, p.ex., pode-se concentrar apenas nas sensações de uma pequena região abaixo do nariz. Nessa meditação focada devem ser observadas a mais sutil mudança de temperatura da pele, a passagem de ar da respiração ou mesmo a pulsação do batimento cardíaco nas veias. Esse tipo de atenção direcionada também pode ser deslocada pelo corpo. Na prática de atenção plena chamada "varredura corporal" [Body-Scan], os participantes devem se concentrar sucessivamente em diferentes partes do corpo e conscientemente observar as suas sensações bem como as não-sensações. A atenção plena é, nesse tipo de meditação, o "observador interno", que nota quando ocorre uma distração e que traz de volta a atenção para o objeto ou para a atividade focada. A segunda técnica cognitiva consiste em repousar toda a atenção não-direcionada na percepção de todas as impressões sensoriais do presente. De momento a momento, devem ser observadas todas as sensações alteradas do corpo, processos mentais e eventos do espaço circundante, sem examiná-los ou reagir a eles. Uma típica instrução para isso consiste em observar todos os pensamentos e percepções como nuvens passageiras, sem querer segurá-las ou alterá-las.

\section{Correlatos neurobiológicos da atenção plena}

Cada vez mais trabalhos empíricos relatam as conexões entre parâmetros neurobiológicos e estados alterados de consciência por meio da meditação. "Enquanto um enorme progresso tem sido feito para identificar correlatos neurais da consciência, aspectos cruciais ainda são muito controversos" (Raffone et al., 2009, 161). Acima de tudo, a comparação direta das muitas novas descobertas é problemática, pois, além de diferentes instrumentos de medição para a registro da atenção plena, também são usados diferentes métodos de meditação (ver Heidenreich et al., 2007, 211). Muitos estudos examinaram e confirmaram a importância central do córtex pré-frontal para a prática da atenção plena. Assim como já mencionado na apresentação das descobertas neurofisiológicos para a vivência-do-fluxo [Flow-Erleben], trata-se aqui de uma região cerebral responsável pelo controle voluntário da ação [willentliche Handlungssteuerung] e pelo direcionamento consciente da atenção [bewusste Aufmerksamkeitslenkung]. As descobertas ainda parcialmente contraditórias são atribuídas, por Lutz et al. (2008), às diferentes formas de direcionamento da atenção durante a meditação. Quando a atividade cerebral é medida em uma forma de meditação não-direcionada, observa-se apenas uma baixa atividade nas regiões pré-frontais. As regiões do córtex sensorial, que são responsáveis pela percepção sensorial, mostraram, em contrapartida, uma maior atividade. Se a pessoa que medita consegue abrir sua atenção de uma maneira não-direcionada para a experiência de todos os sentidos, então não é mais necessário nenhum direcionamento voluntário da atenção (ver Lutz et al., 2008, 164f). O padrão de ativação neuronal descrito assemelha-se ao do estado de fluxo, que também leva à regulação reduzida [Downregulation] do córtex pré-frontal, bem como ao aumento da ativação no córtex sensorial (Goldberg, Harel \& Malach 2006, 337). ). Nas pesquisas atuais, no entanto, não existem estudos que comparem diretamente os estados de consciência da vivência-do-fluxo [Flow-Erle- 
ben] e da atenção plena [Achtsamkeit] um com o outro.

No tipo de meditação com a atenção focada, há um claro aumento na atividade do córtex pré-frontal. Em monges-zen com uma extensa experiência de meditação, de mais de 44.000 horas, mostrou-se, porém, um efeito oposto de uma regulação reduzida [Downregulation]. Isso foi explicado pelos autores no sentido de que esses monges não precisam mais de um esforço voluntário para se focar em um objeto. Atingir esse nível de consciência é referido na psicologia budista como "Samadhi" e é a capacidade do espírito de manter direcionado o foco ininterruptamente em um objeto (ver Wallace, 2008, 184).

\section{Uso do conceito de atenção plena no decorrer do trabalho}

Baseado nos resultados da pesquisa neurofisiológica de Lutz et al. (2008), postula-se que não existem apenas dois tipos de prática de atenção plena, mas que é necessário distinguir também entre duas formas diferentes de atenção plena em si. De um lado, por meio de uma voluntária focalização da atenção surge uma atenção plena para a atividade presente. Isso pode ser, na meditação, uma intensa observação de uma parte do corpo ou, p.ex., da respiração. Essa "atenção plena direcionada" é baseada em uma ação consciente como, p.e.x, ao comer ou enxaguar. A segunda forma de atenção plena será referida daqui em diante como "atenção plena não-direcionada", que inclui uma percepção consciente de todas as impressões sensoriais, bem como todos os pensamentos, sentimentos e impulsos de ação, sem reagir imediatamente a eles. A atenção plena não-direcionada corresponde a um observador interno com uma atitude de aceitação. Aqui a atenção não está limitada a uma atividade determinada ou a um fragmento da janela da percepção. Ela repousa completamente e não-intencionalmente [absichtslos] no presente.

\section{Atenção plena no contexto terapêutico}

A seguir, a aplicação das técnicas de atenção plena será considerada dentro de um contexto terapêutico. Para isso, diferentes abordagens e diferentes processos de medição da atenção plena serão apresentados.

\section{O paradoxo da não-intencionalidade intencional}

A maioria das aplicações psicoterapêuticas esforçam-se consistentemente para fortalecer o EU, melhorar a auto-estima e, assim, também aumentar a qualidade de vida. Os objetivos são, portanto, geralmente muito específicos. Na psicologia budista, no entanto, essa dimensão individual é eliminada. Os exercícios de meditação têm um caráter universal e não psicoterapêutico. A meditação é um caminho que deve levar à iluminação, a um despertar. O caminho espiritual é sobre desenvolver uma percepção aguçada, tornar-se plenamente consciente das próprias experiências e "libertar-se das amarras dos desejos e aversões" (Großmann 2006, 97). Enquanto o centro de gravidade dos métodos de terapia ocidentais residiu por um longo tempo quase exclusivamente na modificação do comportamento, emoção, cognição ou 
sintomas (corporais); nas abordagens baseadas em atenção plena enfatiza-se fortemente o princípio da aceitação (ver Heidenreich \& Michalak 2003, 267). Muitas vezes pensa-se que no contexto de uma terapia o terapeuta elimina ou pelo menos ajuda a resolver os problemas do paciente. Em contrapartida a isso, há na atenção plena uma aceitação do presente. Isso não significa que tudo é denominado como bom, mas apenas que, em um primeiro passo, a situação atual é totalmente percebida, sem desaparecer em âmbitos individuais ou ser pensado "Isso não pode ser verdade!". Existe uma dialética entre modificação e aceitação. Aceitar as coisas como elas são é visto como um pré-requisito para que elas possam se modificar. Essa atitude interna de não-intencionalidade intencional é ainda mais paradoxal dentro de um sistema de saúde que financia apenas terapias baseadas em evidências, que precisam produzir grandes efeitos no menor tempo possível.

\section{Abordagens terapêuticas baseadas em atenção plena}

O biólogo americano e médico Jon Kabat-Zinn deu os primeiros passos, no final da década de 70, para aplicar o conceito de atenção plena em ambientes psicoterapêuticos, por meio de seu treinamento-em-redução-de-estresse baseado em atenção plena $(\mathrm{MBSR})^{8}$. Atualmente, há um grande número de estudos randomizados demonstrando a eficácia de terapias baseadas em atenção plena (ver Bishop et al., 2004, 230ff). As seguintes terapias baseiam-se em atenção plena ou pelo menos contêm módulos individuais que pretendem ter uma conexão e um apoio [nela]: no tratamento de transtornos de personalidade limítrofe, a "psicoterapia behaviorista dialética" (DBT) foi usada com sucesso por Linehan (1996). Os pacientes aprendem, por meio do aprendizado em atenção plena, a aumentar o seu controle de impulsos e, assim, p.ex., refrear comportamentos auto-destrutivos. Também se mostrou eficaz a "terapia de aceitação e comprometimento" (ACT) para os transtornos de ansiedade generalizada (ver Hayes \& Smit de 2006, Luoma et al. 2009). A particularidade dessa abordagem terapêutica consiste em, além do aprendizado em atenção plena, antes de tudo em enfatizar a importância de valores para uma orientação comportamental: "valores são direções de vida escolhidos" (Hayes \& Smith de 2006, 150). Os pacientes são encorajados a se tornarem conscientes de seus valores e a vivê-los com base em uma atitude atenta, apesar das barreiras que aparecem (cf. Heidenreich e Michalak 2006, 237). Em distúrbios de dor, a já mencionada "redução de estresse baseada em atenção plena" (MBSR) foi comprovada (ver Kabat-Zinn 1991) e em doenças depressivas a "terapia cognitiva baseada em atenção plena" (MBCT), de Segal, Williams e Teasdale (2008). Acima de tudo, essas abordagens focam no aprendizado em percepção corporal como uma âncora do presente, no intuito de reconhecer sinais de estresse e sintomas depressivos em um estágio inicial e reagir apropriadamente a eles. Para um resumo das diferentes abordagens terapêticas, veja Michalak, Heidenreich e Bohus (2006, 242ff). Nyklíček, van Son e Pouwer (2010, 613ff) fornecem uma visão geral de meta-análises recentes sobre estudos de eficácia de métodos individuais.

Os métodos descritos acima podem ser classificados principalmente no contexto das terapias comportamentais. Eles se caracterizam por meio de definições ope- 
racionais claras e instrumentos de medição derivados deles, que serão brevemente apresentados abaixo.

\section{Medição empírica da atenção plena}

Métodos de medição adequados são um pré-requisito importante não apenas para a avaliação de abordagens terapêuticas baseadas em atenção plena, mas também para a pesquisa geral desse estado de consciência. Para a medição empírica da atenção plena há uma série de questionários amplamente validados, dos quais quatro dos métodos mais usados serão brevemente apresentados aqui. Esses são: a Mindful Attention Awareness Scale (MAAS), de Brown \& Ryan (2003), a Toronto Mindfulness Scale (TMS), de Bishop, publicada em Lau et al. (2006), o Kentucky Inventory of Mindfulness Skills (KIMS), de Baer, Smith \& Allen (2004), e o Freiburger Fragebogen zur Achtsamkeit (FFA), de Walach et al. (2006). O MAAS mede o quão fortemente uma pessoa, no sentido de traços da personalidade, tende a direcionar a sua atenção para o momento presente. A TMS, por outro lado, captura a atenção em vez do estado atual. Ela foi desenvolvida principalmente para poder demonstrar os efeitos da prática de meditação. O KIMS tenta capturar os diferentes aspectos da atenção plena em subescalas individuais. Em sua construção, ele se orientou principalmente pela abordagem terapêutica baseada na atenção plena de Linehan (DBT). No presente trabalho, decidiu-se usar o FFA. Este instrumento de medição de língua alemã foi construído em uma referência explícita à raiz budista do conceito de atenção plena (ver Walach 2006, 727ff). Uma descrição mais detalhada deste instrumento é fornecida na parte de métodos. Para uma introdução mais abrangente aos diagnósticos gerais da atenção plena, ver Michalak, Heidenreich \& Bohus (2006, 246ff).

\section{Princípios ativos da atenção plena}

A seguir serão descritos os mecanismos subjacentes à atenção plena que possuem um efeito terapêutico. Isso inclui, antes de tudo, a referência ao presente, o aumento da força de vontade e, portanto, também uma alterada interação de sentimentos e impulsos de ação, a sensação corporal consciente e, por último, uma atitude interna especial de atenção plena e aceitação do terapeuta.

\section{Em contato com o presente}

Atenção plena ajuda a desativar o chamado "modo piloto automático" e a interromper estados de ponderação, medos e hábitos comportamentais não-saudáveis. A atenção plena possibilita o libertação de irrefletidas amarras de antigos padrões de comportamento e de vida. Isso é feito pelo distanciamento das próprias memórias, sentimentos e juízos de valor, de modo que, apesar dos conteúdos mentais do presente serem trazidos para a consciência [Kenntnis], eles são ao mesmo tempo reconhecidos apenas como uma das muitas interpretações possíveis da realidade. Eles não são idênticos à realidade. $O$ critério decisivo aqui é a referência ao presente. $A$ "ponderação" sobre o passado designada como ruminação, a preocupação com o fu- 
turo, ou simplesmente também sonhar acordado são, nesse sentido, atitudes do espírito "não-atentas" [unachtsame], porque elas atrapalham e distorcem a percepção de experiências no presente. $O$ reconhecimento consciente desses processos, que geralmente ocorrem automaticamente, e o distanciamento ativo em relação a eles possibilita a libertação de uma direcionada busca [getriebenen Such] por experiências positivas e por uma rejeição de experiências negativas. Estar atento significa, semelhantemente à vivência-do-fluxo, permanecer com toda sua atenção no presente.

\section{Lidando com sentimentos e força de vontade}

Evitar a percepção e as brigas com as emoções problemáticas pode levar a estratégias de enfrentamento disfuncionais e, assim, a sintomas frustantes [belastenden]. "A capacidade do paciente de reconhecer e suportar as emoções problemáticas e diferenciá-las em um caráter adaptativo ou inadaptativo contribui significativamente para a saúde psíquica. É por isso que o desenvolvimento de uma percepção atenta para as emoções e para a aceitação delas é um componente central de qualquer psicoterapia" (Lammers de 2006, 292). Para uma ação atenta, contrária aos impulsos emocionais atuais, necessita-se de certa força de vontade. Um exemplo disso seria a ruptura de um ciclo de sintomas depressivos. Isso pode ser representado assim: humor negativo leva a um comportamento de isolamento [Rückzugsverhalten], mais isolamento leva à falta de experiências positivas e isso, novamente, leva ao fortalecimento da sintomática depressiva. Neste contexto, por meio da atenção plena, pode-se cultivar a capacidade de demostrar comportamentos não correspondentes ao humor atual, que podem, porém, a longo prazo mostrar um efeito positivo. No chamado "aumento de atividades positivas" [positiven Aktivitätenaufbau], os pacientes devem, p.ex., caminhar, ir ao cinema ou dançar, mesmo que eles não sintam nenhuma vontade de fazê-lo (ver Margraf 2000,127). Para isso, é preciso força de vontade para superar a falta de vontade [Unlust] e realizar, mesmo assim, o comportamento. Mesmo sem poder provar isso com estudos empíricos, pode-se supor que a prática de meditação treina essa habilidade. Na meditação sentada, p.ex., concentra-se voluntariamente em algo e, apesar do surgimento, p.ex., de uma coceira ou mesmo de uma dor intensa, deve-se resistir contra os impulsos por meio da força de vontade.

\section{O corpo como âncora do presente}

O primeiro fundamento da atenção plena é o corpo. A percepção consciente do corpo, ou seja, das sensações corporais serve como âncora de orientação para o presente. Ela forma a base para a atenção plena direcionada continuamente para as sensações e estados do espírito [Geisteszustände] (pensamentos). Estes são muito mais difíceis de observar sem se perder neles (ver Bookheld e Walach 2006, 32f).

Abordagens de terapia corporal também colocam em uso o efeito do aprendizado em atenção plena. Ron Kurtz, o fundador da Terapia Hakomi, integrou, já nos anos 60, ideias budistas em seu método terapêutico de psicologia profunda. Aqui, ele fala de "atenção plena interna" e salienta a importância da atenção plena direcionada para dentro do corpo, no intuito de tornar acessível para o processo psicoterapêutico 
o material não-consciente. "Esta abordagem revela a possibilidade em si de apaziguar o desejo [Sehnsucht] dos pacientes por um contato direto com o mundo e consigo mesmo" (Wurll 2007, 69).

Uma atitude atenta promove a percepção e o cumprimento das próprias necessidades e pode, assim, ser eficaz, por exemplo, na prevenção do esgotamento [Burn-out]. No esgotamento, a carga de trabalho ultrapassa as reservas de energia do corpo, mas, em vez de ouvir os sinais do corpo e fazer pausas relaxantes, os pacientes do esgotamento tendem a continuar sobrecarregando a si mesmos. (Harrer ver. 2008, 6).

\section{A atitude atenta do terapeuta}

Carl Rogers, o fundador da psicoterapia centrada na pessoa, estava convencido de que revelar determinas atitudes, que ele chamou de "variáveis centrais do encontro humano", iria incentivar um processo de crescimento nos seres humanos. Esta força orientada para o desenvolvimento foi denominada por ele de tendência à auto-atualização (cf. Bundschuh 2006, 1). Wurll $(2007,69)$ descreve essas variáveis centrais no sentido de uma atitude terapêutica consciente, da seguinte forma: primeiro, trata-se de estabelecer um espaço seguro que encorage a reflexão e a investigação do "mundo interno". Para isso, é necessária uma atitude de aceitação e não-julgamento diante de tudo que emergir. O terapeuta continua convidando para uma observação atenta, em vez de querer mudar algo.

Segundo Heidenreich e Michalak $(2006,232)$, também existem paralelos entre o conceito de atenção plena e a atitude psicanalítica de "atenção flutuante" [gleich schwebenden Aufmerksamkeit]. Análogo a isso, encontram-se também claros paralelos em abordagens humanistas como, p.ex., o princípio da "presença" na terapia Gestalt (Perls 2002) e no "Focusing", de Gendlin (1981).

\section{Atenção plena e a importância do sentir}

Um novo aspecto e essencial desenvolvimento da psicoterapia centrada na pessoa foi introduzido por Eugene Gendlin, colega de trabalho de longa data de Rogers. Ele apontou para a importância da vivência (Experiencing) corporal sentida no presente. "Quando os clientes recorrerem diretamente ao sentir do momento, ao incerto [Unklaren], para o qual não há nenhuma palavra ou imagem, isso é um passo decisivo para uma mudança terapêutica" (Bundschuh-Müller, 2006, 3). O senso corporal de uma situação (Felt Sense) é o tipo e o modo como o corpo experiencia o momento presente. O senso sentido [Felt Sense] está sempre ligado ao presente enquanto uma vivência integral. Por meio da sua consciente capacidade de sentir [bewusstes Erspüren], ele pode representar uma importante ajuda de orientação para os processos de desenvolvimento e de tomada de decisão (veja ibid).

Sentir, no contexto da atenção plena, significa também realmente se entregar às suas percepções sensoriais. Na terapia eutimia, "a pequena escola do prazer", de Lutz (2000), são apresentadas, p.ex., regras de prazer que correspondem diretamente aos princípios da atenção plena. Estes seriam, p.ex.: "prazer leva tempo" ou "prazer não ocorre por acaso" (ver Lutz 2000, 447ff). Em um comer atento, o foco de atenção 
repousa no "saborear". Há, no entanto, também uma consciência sobre quando aparece o sentimento de saciedade, e sobre quanto foi consumido no total (ver Brown \& Ryan 2003, 823).

\section{Correlações com a qualidade de vida}

A seguir, será descrita a saúde corporal e psíquica em correlação com a prática da atenção plena. Posteriormente, em vista da questão central deste presente trabalho, entrar-se-á especialmente no bem-estar subjetivo.

\section{Saúde corporal e psíquica}

O aprendizado e a prática da atenção plena mostra, mesmo fora de contextos clínicos, um efeito positivo na qualidade de vida. Assim pôde mostrar Ayan (2007) em estudos de correlação: uma elevada atenção plena anda junto com um aumentado sentimento de autoeficácia. Junto da atenção plena aumenta a convicção de poder influciar ativamente o próprio destino e não se ver como vítima de circunstâncias incontroláveis. Isso está relacionado a uma maior auto-estima e uma melhor auto-aceitação das pessoas (ver Ayan 2007, 82ff).

Mück-Weymann (2007) fornece um panorama dos efeitos positivos da meditação regular na saúde corporal e em comportamentos saudáveis. Em comparação direta com pessoas sem uma prática regular de atenção plena, foram registradas quase $60 \%$ menos hospitalizações. Além disso, grupos de meditação mostraram um comportamento de consumo significativamente menor de café (25\%), nicotina (45\%), álcool e drogas (30\%) (ver Mück- Weyman. 2007, 188).

\section{Atenção plena e bem-estar subjetivo}

Em um estudo muito citado, de Brown e Ryan (2003), foram mostradas correlações negativas de atenção plena com escalas de depressão (BDI de Beck, 1993) e também com a escala de sensações negativas [Affekt-Skala] da PANAS (Watson et al., 1988). Correlações positivas foram encontradas na satisfação cognitiva com a vida (SWLS, de por Diener et al., 1985) e na escala de sensações positivas da PANAS (ver Brown \& Ryan 2003, 829). Na maioria dos estudos de atenção plena, apenas inteiros programas de terapia são avaliados quanto à eficácia. Brown e Ryan (2003), no entanto, puderam demonstrar, usando a escala MAAS desenvolvida por eles, que o melhoramento do SWB [bem-estar subjetivo] realmente pode ser remetido à mudança do modelo de atenção plena (Brown e Ryan 2003, 840ff). Em um estudo posterior, Brown et al. (2009) pesquisarem até que ponto a atenção plena afeta a satisfação financeira dos funcionários. Os participantes foram questionados sobre quanto ganhavam e sobre quanto gostariam de ganhar. Aqui, mostrou-se que essa discrepância era tanto menor, quanto mais atento [achtsamer] era o entrevistado. Os autores interpretaram os seus resultados do seguinte modo: "Atenção plena promove a percepção de ter o suficiente" (Brown et al 2009, 727). Atenção plena promove um contentamento e aceitação da situação atual, o que leva a uma avaliação mais positiva 
do bem-estar subjetivo.

Em um estudo com uma linha de raciocínio muito semelhante, as correlações entre atenção plena, prática de meditação, consciência ambiental [Umweltverhalten] e SWB foram investigadas. Em uma amostra de 829 participantes do estudo, ficou muito claro que a atenção plena e a tamanho da prática de meditação estão significativamente relacionados à consciência ambiental sustentável e ao bem-estar subjetivo. Aqui, os autores também viram evidência para o pressuposto do princípio de atenção plena de que a percepção consciente acerca de sentimentos e circunstâncias desagradáveis (como, p.ex., a destruição ambiental) não conduz necessariamente a uma menor satisfação com a vida (ver Jacob et al. 2009, 275ff).

Em resumo, é possível afirmar que a atenção plena tem um efeito positivo comprovado na qualidade de vida percebida subjetivamente, não apenas no contexto terapeutico, mas também na vida cotidiana.

\section{Reflexão crítica sobre a atenção plena}

Assim como na vivência-do-fluxo, uma representação positiva unilateral da (pesquisa sobre) atenção plena gera a uma legítima pergunta, sobre a existência de pontos críticos.

\section{Atenção plena enquanto conceito desenraizado}

Para a integração da atenção plena nas formas ocidentais de psicoterapia, ela foi removida do seu contexto espiritual-religioso original e foi mais ou menos isolada, rearranjada e praticada. Como já foi descrito, a atenção plena em seu núcleo essencial não se encaixa em um sistema de saúde constantemente orientado para eficácia e eficiência. "A integração da atenção plena e da aceitação no sistema de saúde requer, portanto, muita sensibilidade, caso não se deseje dobrar e distorcer o núcleo central desses princípios" (Michalak et al., 2006, 249). Assim se expressam organizações como, p.ex., a Associação Vipassana, a qual se vê na tradição dos ensinamentos de sabedoria budistas, de forma completamente crítica diante das tentativas de pesquisas terapêuticas que retiram a atenção plena do seu contexto originário e a ensinam como um módulo singular. ${ }^{9}$

\section{Grupos-alvo e contra-indicações da prática de atenção plena}

Uma outra consideração crítica aponta para o perigo de proclamar a atenção plena como uma panacéia para tudo e todos. Bishop (2002) sugeriu que terapias baseadas em atenção plena só seriam eficazes para um subgrupo de pacientes, e que os efeitos significativos poderiam ser devidos a processos de expectativa. “É bem possível que a eficácia desta abordagem tenha mais a ver com o tipo de pessoas que são atraídas por ela do que com a abordagem em si" (Bishop 2002, 76). A prática da aten-

${ }^{9}$ Comunicação pessoal de um instrutor de meditação Vipassana em Triebel 2009 (URL: http://www.dvara.dhamma.org, acessado em 23.3.2010). 
ção plena não é para todo mundo, nem é o método correto para todas as situações da vida. Ela não é adequada como um modo terapêutico obrigatório, mas, sim, deveria ser praticada voluntariamente. No entanto, entender os efeitos positivos das formas de terapias baseadas em atenção plena como efeitos-placebo parece bastante improvável em vista dos mencionados estudos de avaliação, controlados e randomizados.

“Uma prática de atenção plena séria requer perseverança, confiança, paciência e um nível não irrelevante de capacidade para sofrer" (Anderssen-Reuster 2007, 59). A principal tarefa do terapeuta de atenção plena consiste em fortalecer a disposição de seus clientes em querer lidar com sua realidade e com todo o sofrimento contido nela. Na terapia de trauma, entretanto, supõe-se que o mecanismo de supressão de nossa psique, como, por exemplo, a perda de memória após experiências dramáticas, é principalmente colocada como uma função de proteção. Na prática da atenção plena, vêem repetidamente à superfície, apesar do foco específico para o presente, conteúdos da consciência que são reprimidos no cotidiano. Assim, um rápido confronto com memórias de trauma em pessoas que ainda não foram suficientemente estabilizadas poderia levar a uma nova traumatização (ver Foa et al., 1999, 107ff).

De acordo com Fiedler (2006), métodos baseados em atenção plena possuem limites claros: exercícios de atenção plena são insuficientes em muitos casos; eles são, segundo sua opinião, às vezes até mesmo obstáculos. Enraizado o transtorno depressivo, p.ex., em uma situação de vida difícil como, p.ex., uma separação ou quando uma pessoa foi vítima de um ato violento, então a tentativa de aceitação sem julgamentos poderia até mesmo agravar a crise psicológica. Fiedler pede, portanto, cautela: uma atitude "tudo está bom como está" não deveria substituir uma direcionada conversa terapêutica em situações de crise (ver Fiedler 2006, 269).

\section{Resumo sobre a atenção plena e referências para o questionário}

A atenção plena foi descrita como uma habilidade meta-cognitiva, que foca a própria atenção para o momento presente e, com isso, observa os próprios pensamentos, sentimentos e impulsos de ação com boa vontade e com aceitação [wohlwollend und akzeptierend], sem reagir imediatamente. Isso não significa, todavia, que tudo deva, ao mesmo tempo, ser chamado de bom.

A atitude de atenção plena possiblita agir conscientemente também em experiências e dificuldades desagradáveis, guiada por valores e objetivos, bem como apoiada em uma elevada força de vontade. O efeito terapêutico da atenção plena foi atribuído, tanto no contexto clínico quanto no cotidiano, à capacidade de distanciar-se da própria vivência sem, com isso, p.ex., restringir a percepção de todos os sinais corporais ou das informações de um contexto.

Em um reflexão mais precisa sobre a meditação como uma prática de atenção plena, foi diferenciada entre a meditação focada em um objeto ou em atividade, e a meditação não-direcionada e aberta. Enquanto na primeira forma é buscada uma intenção como, p.ex., observar com precisão as sensações de uma determinada região do corpo; na segunda técnica de meditação a janela da atenção é aberta para todas as percepções e somente é buscada uma intenção de não-intencionalidade. 
Por meio dessa prática, pode-se chegar em uma dissolução da consciência-do-eu e, portanto, em um estado transpessoal de consciência.

Apesar dos pontos de crítica apresentados, os efeitos positivos da atenção plena na qualidade de vida subjetiva não podem ser negados. A atenção plena oferece a possibilidade de um comportamento consciente, de modo que o bem-estar subjetivo possa ser maximizado. "Atenção plena pode ser vista como uma forma de vida com transições para o tradicional conceito de arte de viver, que compreende a concepção consciente da existência como uma forma de arte" (Altner 2007, p 155f). A capacidade de trazer atenção e espaço para o estado interno, e levá-los em consideração também nos momentos de pequenas e grandes decisões do cotidiano, é uma importante base para se configurar um estilo de vida único e harmonioso [individuell stimmigen].

Como conclusão do capítulo "pano de fundo teórico" será apresentado, agora, a forma de dança Contato Improvisação.

\section{Referências $^{10}$}

Altner, N. (2007). Stressbewältigung durch Achtsamkeit als Intervention für Menschen mit chronischen Schmerzen. In: U. Anderssen-Reuster (Hrsg): Achtsamkeit in Psychotherapie und Psychosomatik. Stuttgart: Schattauer, 148-158.

Anderssen-Reuster, U. \& Altner, N. (2007). Ich - Stärkung oder Selbst-Überwindung? In: U. Anderssen-Reuster (Hrsg): Achtsamkeit in Psychotherapie und Psychosomatik. Stuttgart: Schattauer, 53-65.

Ayan, S. (2007). Willkommen im Hier und Jetzt. Gehirn \& Geist, 07 (3), 78-84.

Baer, R., Smith, G. \& Allen, K. (2004). Assessment of mindfulness by self-report. The Kentucky Inventory of Mindfulness Skills. Assessment, 11, 191-205.

Beck, A. (1993). Hopelessness, depression, suicidal ideation, and clinical diagnosis of depression. Suicide and Life Threatening Behavior, 23 (2), 139-145.

Bishop, S. (2002). What do we really know about mindfulness-based stressreduction? Psychsomatic Medicine, 64, 71-81.

Bishop, S. R., Lau, M., Shapiro, S., Carlson, L., Anderson, N. D., Carmody, J., Segal, Z. V., Abbey, S., Speca, M., Velting, D. \& Devins, G. (2004). Mindfulness: A proposed operational definition. Clinical Psychology - Science and Practice, 11(3), 230-241.

Brown, K. \& Ryan, R. (2003). The Benefits of Being Present: Mindfulness and Its Role in Psychological Well-Being. Journal of Personality and Social Psychology, 84 (4), 822-848.

${ }^{10}$ [Trago aqui somente uma parte das referências bibliográficas da Tese de Doutorado de Schmid, ou seja, somente aquilo que ele citou nesses trechos traduzidos.] 
Brown, K. W., Kasser, T., Ryan, R. M., Linley, P. A. \& Orzech, K. (2009). When what one has is enough: Mindfulness, financial desire discrepancy and subjective well-being. Journal of Research in Personality, 43 (5), 727-736.

Buchheld, N. \& Walach, H. (2006). Die historischen Wurzeln der Achtsamkeitsmeditation. Ein Exkurs in Buddhismus und christliche Mystik. In: T. Heidenreich \& J. Michalak (Hrsg.): Achtsamkeit und Akzeptanz in der Psychotherapie. Tübingen: dgvt-Verlag, 26-46.

Bundschuh, K. (2006). Akzeptieren heißt Verändern. Aus der Praxis. Gesellschaft für wissenschaftliche Gesprächspsychotherapie e. V.. URL: http://www.gwg-ev.org/docs/2007-01-09-bundschuh-mueller.pdf, Zugriff am 22.3.2007.

Diener, E., Emmons, R.A., Larsen, R.J. \& Griffin, S. (1985). The Satisfaction with Life Scale. Journal of Personality and Assessment, 49, 71-75.

Edelman, G. \& Tononi, G. (2000). A Universe of Consciousness. New York: Basic books.

Fiedler, P. (2006). Psychotherapie in der Entwicklung. Verhaltenstherapie und Psychosoziale Praxis, 38, 269-282.

Foa, B., Olasov Rothbaum, B. \& Maercker, A. (1999). Posttraumatische Belastungsstörungen. In: J. Margraf (Hrsg): Lehrbuch der Verhaltenstherapie. Band 1. Grundlagen, Diagnostik, Verfahren, Rahmenbedingungen. Berlin: Springer, 447-463.

Gendlin, E. (1981). Focusing. New York: Bantam.

Goldberg, I. I., Harel, M. \& Malach, R. (2006). When the Brain Loses Its Self: Prefrontal Inactivation during Sensorimotor Processing. Neuron, 50 (2), 329-339.

Großmann, P. (2006). Das Üben von Achtsamkeit. In T. Heidenreich (Hrsg.): Achtsamkeit und Akzeptanz in der Psychotherapie. Tübingen: dgvt-Verl., 69-102.

Hayes, S. \& Smith, S. (2006). Get out of your mind and into your life. Oakland, Cf.: New Harbinger Publ.

Heidenreich, T. \& Michalak, J. (2003). Achtsamkeit (Mindfulness) als Therapieprinzip in Verhaltenstherapie und Verhaltensmedizin. Verhaltenstherapie, 13, 264-274.

Heidenreich, T. \& Michalak, J. (2006). Einführung in die Thematik Achtsamkeit und Akzeptanz in der Psychotherapie. Zeitschrift für Psychiatrie, Psychologie und Psychotherapie, 54 (4), 231-240.

Heidenreich, T., Junghanns, K., Royack, K. \& Michalak, J. (2007). Achtsamkeitsbasierte Therapieansätze: Stand der Forschung. In U. Anderssen-Reuster (Hrsg). Achtsamkeit 
in Psychotherapie und Psychosomatik. Stuttgart: Schattauer, 202-216.

Jacob, J., Jovic, E. \& Brinkerhoff, M. B. (2009). Personal and Planetary well-being: Mindfulness Meditation. Pro-environmental Behavior and Personal Quality of Life in a Survey from the Social Justice and Ecological Sustainability Movement. Social Indicators Research, 93 (2), 275-294.

James, W. (1958). The Principles of Psychology. New York: Dover Publications.

Kabat-Zinn, J. (1991). Gesund durch Meditation. München: Barth.

Lammers, C. (2006). Achtsamkeit und Akzeptanz bei der therapeutischen Arbeit an Emotionen. Achtsamkeit und Akzeptanz. Aus der Praxis, (7) 292-296.

Lau, M., Bishop, R., Segal, Z., Buis, T. , Anderson, N., Carlson, L., Shapiro, S. \& Carmody, J. (2006). The Toronto Mindfulness Scale: Development and Validation. Journal of Clinical Psychology, 62 (12), 1445-1467.

Linehan, M. (1996). Dialektisch-behaviorale Therapie der Borderline-Persönlichkeitsstörung. München: CIP-Medien.

Luoma, J. B., Hayes, S. C., Walser, R. D. \& Kierdorf, T. (2009). ACT-Training. Paderborn: Junfermann.

Lutz, A., Slagter, H. A., Dunne, J. D. \& Davidson, R. J., (2008). Cognitive-emotional interactions - Attention regulation and monitoring in meditation. Trends in Cognitive Sciences, 12 (4), 163-169.

Lutz, R. (2000). Eutyme Therapie. In: J. Margraf (Hrsg.): Lehrbuch der Verhaltenstherapie. Band 1. Grundlagen, Diagnostik, Verfahren, Rahmenbedingungen. Berlin: Springer, 447-463.

Margraf, J. (2000). Lehrbuch der Verhaltenstherapie. Band 2. Berlin: Springer.

Michalak, J., Heidenreich, T. \& Bohus, M. (2006). Achtsamkeit und Akzeptanz in der Psychotherapie. Gegenwärtiger Forschungsstand und Forschungsentwicklung. Zeitschrift für Psychiatrie, Psychologie und Psychotherapie, 54 (4), 241-253.

Mück-Weymann (2007). Einige psychophysiologische Überlegungen zur Meditation. In: U. Anderssen-Reuster (Hrsg.): Achtsamkeit in Psychotherapie und Psychosomatik. Stuttgart: Schattauer, 187-201.

Nyklíček, I. , van Son, J. \& Pouwer, F. (2010). Two recently published meta-analyses on the effectiveness of mindfulness-based interventions: What should the reader make of it? Journal of Psychosomatic Research, 69 (6), 613-614. 
Perls, F. (2002). Grundlagen der Gestalt-Therapie. Einführung und Sitzungsprotokolle. Stuttgart: Klett-Cotta.

Raffone, A. \& Srinivasan, N. (2009). An adaptive workspace hypothesis about the neural correlates of consciousness: insights from neuroscience and meditation studies. Progress in Brain Research;176, 161-180.

Rinpoche, S. (1995). Funken der Erleuchtung. Bern: Barth. (Dieses Buch besitzt keine Seitenzahlen, sondern nur Kalendertage).

Segal, Z. V., Williams, J. M. G. \& Teasdale, J. D. (2008). Die achtsamkeitsbasierte kognitive Therapie der Depression. Tübingen: dgvt-Verlag.

Walach, H., Buchheld, N., Buttenmüller, V., Kleinknecht, N., Grossman, P. \& Schmidt, S. (2006). Empirische Erfassung der Achtsamkeit - Die Konstruktion des Freiburger Fragebogens zur Achtsamkeit (FFA) und weitere Validierungsstudien. In T. Heidenreich, J. Michalak, (Hrsg): Achtsamkeit und Akzeptanz in der Psychotherapie. Tübingen: dgvt-Verlag, 727-770.

Wallace, A. \& Kahn-Ackermann, S. (2008). Die Achtsamkeits-Revolution. Frankfurt am Main: Scherz.

Watson, D., Clark, L.A. \& Tellegen, A. (1988). Development and validation of brief measures of positive and negative affect: The PANAS scales. Journal of Personality and Social Psychology, 54 (6), 1063-1070.

Wurll, P. (2007). Achtsamkeit als therapeutische Grundhaltung. In: U. Anderssen-Reuster (Hrsg). Achtsamkeit in Psychotherapie und Psychosomatik. Stuttgart: Schattauer, 69-77.

Recebido em: 06/04/2018

Aprovado em: 06/04/2018 